\title{
KARAKTERISTIK NILAI EIGEN DARI MATRIKS LAPLACIAN
}

Siti Rahmah Nurshiami, Mutia Nur Estri, Noor Sofiyati Program Studi Matematika, Fakultas Sains dan Teknik Universitas Jenderal soedirman, Purwokerto E-mail : nurshiami@yahoo.co.id

\begin{abstract}
ABSTRAK. Matriks Laplacian dari suatu graf $G$ adalah matriks diagonal dikurangi dengan matriks ketetanggaan. Paper ini membahas karakteristik nilai eigen dari matriks Laplacian dan hubungan nilai eigen matriks Laplacian dengan nilai eigen matriks ketetanggaan dari graf reguler.
\end{abstract}

Kata kunci : Matriks Laplacian, Nilai Eigen, Nilai Eigen Laplacian, Graf Reguler

ABSTRACT. The Laplacian matrix of a graph $G$ is a diagonal matrix minus the neighborhood matrix. This paper discusses about the characteristics of the Laplacian matrix eigenvalues and the relationships of Laplacian matrix eigenvalues with neighborhood matrix eigenvalues of regular graphs.

Keywords: Laplacian matrix, Eigen Values, Eigen Value Laplacian, Regular Graph

\section{Pendahuluan}

Sebuah graf dapat direpresentasikan ke dalam matriks Laplacian. Jika $D(G)$ merupakan matriks diagonal dengan entri pada diagonal utamanya merupakan derajat dari titik $v_{i}$ pada graf $G$, dan $A(G)$ merupakan matriks ketetanggaan dari graf $G$, maka matriks Laplacian $L(G)$ merupakan matriks bujur sangkar yang diperoleh dari matriks diagonal dikurangi matriks ketetanggaan. Nilai eigen dari matriks Laplacian dapat diperoleh dengan menggunakan polinomial karakteristik. Pada tahun 1973, Fiedler mempelajari salah satu karakteristik nilai eigen dari matriks Laplacian, yaitu nilai eigen terkecil kedua. Sementara itu, Juhasz(1982) mempelajari nilai eigen dari graf reguler beserta multiplisitasnya, yang dikenal dengan spektrum graf. Paper ini mengkaji karakteristik lain nilai eigen dari matriks Laplacian. 


\section{Matriks Laplacian}

Suatu graf dikatakan reguler berderajat $r$ ( $r$-reguler) jika untuk setiap titiknya mempunyai derajat $r$. Misalkan $G=(V, E)$ adalah graf sederhana dengan $n$ titik dan $m$ sisi. Matriks ketetanggaan dari graf $G$ adalah matriks $A_{n \times n}=A(G)$ dengan entri

$$
a_{i j}=\left\{\begin{array}{l}
1, j i k a\left(v_{i}, v_{j}\right) \in E(G) \\
0, j i k a\left(v_{i}, v_{j}\right) \notin E(G)
\end{array}\right.
$$

Matriks insidensi $N$ dari graf berarah $G$ adalah matriks berukuran $n \times m$ dengan entri :

$$
N=\left[n_{\mathrm{ij}}\right]=\left\{\begin{aligned}
+1, & \text { jika titik } v_{i} \text { merupakan titik awal dari sisi } e_{j}=\left(v_{i}, v_{k}\right) \\
-1, & \text { jika titik } v_{k} \text { merupakan titik akhir dari sisi } e_{j}=\left(v_{i}, v_{k}\right) \\
0, & \text { lainnya. }
\end{aligned}\right.
$$

Matriks Laplacian dari graf berarah atau tak berarah $G$ adalah $\mathcal{L}(G)=$ $D(G)$ - $A(G)$ dengan $D(G)$ matriks diagonal dari graf $G$ dan $A(G)$ matriks ketetanggaan dari graf $G$. Matriks $D_{n \times n}=\left[d_{i j}\right]$ merupakan matriks diagonal dari graf $G$ dengan entri

$$
d_{i j}=\left\{\begin{aligned}
\operatorname{der}\left(v_{i}\right), & \text { jika } v_{i}=v_{j} \\
0, & \text { jika } v_{i} \neq v_{j}
\end{aligned}\right.
$$

Dengan demikian, entri matriks Laplacian $\mathcal{L}(G)$ adalah

$$
\mathcal{L}_{n \times n}=\left[l_{i j}\right]=\left\{\begin{aligned}
-1, & \text { jika }\left(v_{i}, v_{j}\right) \in E(G) \\
\operatorname{der}\left(v_{i}\right), & \text { jika } v_{i}=v_{j} \\
0, & \text { jika }\left(v_{i}, v_{j}\right) \notin E(G) .
\end{aligned}\right.
$$

Karakteristik dari matriks Laplacian untuk sembarang graf $\mathrm{G}$ diberikan oleh proposisi berikut;

\section{Proposisi 1 [9]}

Karakteristik matriks Laplacian dari graf $G, \mathcal{L}(G)$ adalah sebagai berikut :

1. Jumlah entri setiap baris pada matriks Laplacian $\mathcal{L}(G)$ sama dengan nol.

2. Matriks $\mathcal{L}(G)$ adalah matriks berukuran $n \times n$ dimana $n$ menyatakan banyaknya titik dari graf $G$.

3. Misalkan $N$ merupakan matriks insidensi dari graf berarah $G$ dengan $n$ titik. Maka matriks Laplacian $\mathcal{L}(G)$ dapat dinyatakan dengan $\mathcal{L}=N N^{t}$ 
4. Perubahan pelabelan sisi pada graf $G$ tidak berpengaruh pada matriks Laplacian $\mathcal{L}(G)$.

5. Matriks $\mathcal{L}(G)$ merupakan matriks singular.

6. Matriks Laplacian $\mathcal{L}(G)$ merupakan matriks simetris dan semidefinit positif.

\section{Nilai Eigen Matriks Laplacian}

Misalkan $G$ adalah graf sederhana dengan $n$ titik dan matriks ketetanggaan dari $G$ adalah $A(G)$. Polinomial karakteristik dari graf $G$ dinotasikan dengan $\chi(G ; \lambda)$, dinyatakan sebagai

$$
\begin{aligned}
\chi(G ; \lambda) & =\operatorname{det}\left(\lambda I_{n}-A(G)\right) \\
& =\lambda^{n}+C_{1} \lambda^{n-1}+C_{2} \lambda^{n-2}+\cdots+C_{n}
\end{aligned}
$$

dengan $\lambda$ adalah nilai eigen dari matriks ketetanggaan $A(G)$. Karena $A(G)=\left[a_{i j}\right]$ $=\left[a_{j i}\right]$, sehingga matriks $A(G)$ adalah matriks riil dan simetri. Akibatnya nilai eigen $\lambda$ adalah bilangan riil, dan multiplisitas dari $\lambda$ adalah dimensi dari ruang eigen yang bersesuaian dengan nilai eigen $\lambda$.

Karakteristik dari suatu graf $G$ reguler berderajat $r$, diberikan dalam proposisi 2 berikut;

\section{Proposisi 2[2]}

Misalkan $G$ adalah graf $r$-reguler dengan $n$ titik. Maka:

i. $\quad r$ adalah nilai eigen dari $G$;

ii. Jika $G$ adalah graf terhubung, maka multiplisitas $r$ adalah 1;

iii. Untuk setiap nilai eigen $\lambda$ dari $G$, berlaku $|\lambda| \leq r$.

Selanjutnya, karakteristik dari nilai eigen matriks Laplacian $\mathcal{L}(G)$ diberikan dalam proposisi 3 berikut;

\section{Proposisi 3}

Jika $\mu_{0} \leq \mu_{1} \leq \ldots \leq \mu_{n-1}$ merupakan nilai eigen dari matriks Laplacian $\mathcal{L}(G)$, maka

i. $\quad \mu_{0}=0$, dengan vektor eigen $[1,1, \ldots, 1]$;

ii. Jika $G$ graf terhubung, $\mu_{1}>0$; 
iii. Jika $G$ graf regular berderajat $k$, maka $\mu_{p}=k-\lambda_{p}$, dengan $p=0,1,2, \ldots, n$ 1 dengan $\mu_{p}$ adalah nilai eigen dari matriks ketetanggaan graf $G$ dengan $\lambda_{0} \geq \lambda_{1} \geq \ldots \geq \lambda_{n-1}$

\section{Bukti :}

i. Misalkan $\mathcal{L}_{n \times n}=\left[l_{i j}\right]$ adalah matriks Laplacian dari $G$. Karena $\mu_{0}$ nilai eigen dari matriks Laplacian $\mathcal{L}(G)$ maka, $\mathcal{L} \mathbf{x}=\boldsymbol{\mu}_{\mathbf{0}} \mathbf{x}$, dengan $x=$ $\left[\begin{array}{llll}x_{1} & x_{2} & \ldots & x_{n}\end{array}\right]^{t}=\left[\begin{array}{llll}1 & 1 & \ldots & 1\end{array}\right]^{t}$ vektor eigen yang bersesuaian dengan $\boldsymbol{\mu}_{\mathbf{0}}$.

Perhatikan bahwa

$$
\begin{aligned}
& \mathcal{L} \mathrm{x}=\mu_{0} \mathrm{x} \\
& \Leftrightarrow\left[\begin{array}{cccc}
l_{11} & l_{12} & \ldots & l_{1 n} \\
l_{21} & l_{22} & \ldots & l_{2 n} \\
\vdots & \vdots & \ddots & \vdots \\
l_{n 1} & l_{n 2} & \ldots & l_{n n}
\end{array}\right]\left[\begin{array}{c}
1 \\
1 \\
\vdots \\
1
\end{array}\right]=\mu_{0}\left[\begin{array}{c}
1 \\
1 \\
\vdots \\
1
\end{array}\right] \\
& \Leftrightarrow \quad\left[\begin{array}{c}
\sum_{j=1}^{n} l_{1 j} \\
\sum_{j=1}^{n} l_{2 j} \\
\vdots \\
\sum_{j=1}^{n} l_{n j}
\end{array}\right]=\left[\begin{array}{c}
\mu_{0} \\
\mu_{0} \\
\vdots \\
\mu_{0}
\end{array}\right] .
\end{aligned}
$$

Karena jumlah entri dari setiap baris pada matriks Laplacian sama dengan nol, maka $\sum_{j=1}^{n} l_{i j}=0$, dengan $i=1,2, \ldots, n$. Akibatnya $\mu_{0}=0$.

ii. Misalkan $\mu_{p}$ dengan $p=0,1, \ldots, n-1$ merupakan nilai eigen dari $\mathcal{L}$. Karena matriks Laplacian $\mathcal{L}(G)$ merupakan matriks semidefinit positif, maka $\mu_{p} \geq 0$. Dari (i) vektor eigen yang bersesuaian dengan $\mu_{0}=0$ adalah vektor $x=\left[\begin{array}{llll}1 & 1 & \ldots & 1\end{array}\right]^{t}$. Sehingga ruang eigen dari $\mathcal{L}$ yang bersesuaian 
dengan nilai eigen $\mu_{0}=0$ dapat ditulis

$R E(0)$

$=\left\{\alpha\left[\begin{array}{llll}1 & 1 & \ldots & 1\end{array}\right]^{t} \mid \alpha \neq 0, \alpha \in R\right\}$.

Selanjutnya dapat dibuktikan bahwa $\left\{(1,1, \ldots, 1)^{t}\right\}$ basis dari $R E(0)$. Jadi, multiplisitas dari nilai eigen $\mu_{0}=0$ adalah 1 . Karena $\mu_{p} \geq 0$ untuk $p=$ $0,1, \ldots, n-1$ dan $\mu_{0}=0$ maka $\mu_{1}>0$.

iii. Misalkan $\lambda$ merupakan nilai eigen dari matriks ketetanggaan $A(G)$, sehingga $A \mathbf{x}_{p}=\lambda_{p} \mathbf{x}_{p}$ dengan $\mathbf{x}_{p} \in \mathbb{R}^{n}, \mathbf{x}_{p} \neq \mathbf{0}, p=0,1,2, \ldots, n-1$.

Karena $\mu$ merupakan nilai eigen dari matriks Laplacian $\mathcal{L}(G)$ sehingga $\mathcal{L}$ $\mathbf{x}_{p}=\mu_{p} \mathbf{x}_{p}$

dimana $\mathbf{x}_{p}$ adalah vektor eigen yang bersesuaian dengan nilai eigen ke $p$ dan $\mathbf{x}_{p} \neq \mathbf{0}$.

Karena $D(G)$ merupakan matriks diagonal dari graf $G$ reguler berderajat $k$ sehingga menurut proposisi 1(i), nilai eigennya adalah $k$. Akibatnya $D \mathbf{x}_{p}=k \mathbf{x}_{p}$.

Dari definisi matriks Laplacian diperoleh $\mathcal{L} \mathbf{x}_{p}=D \mathbf{x}_{p}-A \mathbf{x}_{p}$ untuk suatu $\mathbf{x}_{p} \in \mathbb{R}^{n}$. Akibatnya $\mu_{p} \mathbf{x}_{p}=k \mathbf{x}_{p}-\lambda_{p} \mathbf{x}_{p}$.

Sehingga

$$
\begin{aligned}
& \mu_{p}\left[\begin{array}{c}
x_{1} \\
x_{2} \\
\vdots \\
x_{n}
\end{array}\right]=k\left[\begin{array}{c}
x_{1} \\
x_{2} \\
\vdots \\
x_{n}
\end{array}\right]-\lambda_{p}\left[\begin{array}{c}
x_{1} \\
x_{2} \\
\vdots \\
x_{n}
\end{array}\right] \\
& \Leftrightarrow \quad\left[\begin{array}{c}
\mu_{p} x_{1} \\
\mu_{p} x_{2} \\
\vdots \\
\mu_{p} x_{n}
\end{array}\right]=\left[\begin{array}{c}
k x_{1}-\lambda_{p} x_{1} \\
k x_{1}-\lambda_{p} x_{2} \\
\vdots \\
k x_{1}-\lambda_{p} x_{n}
\end{array}\right] \\
& \Leftrightarrow \quad\left[\begin{array}{c}
\mu_{p} x_{1} \\
\mu_{p} x_{2} \\
\vdots \\
\mu_{p} x_{n}
\end{array}\right]=\left(k-\lambda_{p}\right)\left[\begin{array}{c}
x_{1} \\
x_{2} \\
\vdots \\
x_{n}
\end{array}\right] \\
& \Leftrightarrow \quad \mu_{p} \mathbf{x}_{p}=\left(k-\lambda_{p}\right) \mathbf{x}_{p} .
\end{aligned}
$$

Sehingga $\mu_{p}=k-\lambda_{p} \quad, p=0,1,2, \ldots, n-1$. 


\section{Kesimpulan}

Berdasarkan pembahasan mengenai matriks Laplacian, dapat disimpulkan bahwa jika $\mu_{0} \leq \mu_{1} \leq \ldots \leq \mu_{n-1}$ merupakan nilai eigen dari matriks Laplacian $\mathcal{L}(G)$, maka nilai eigen yang pertama adalah nol dengan multiplisitasnya 1 . Lebih dari itu, jika $G$ graf terhubung maka nilai eigen kedua lebih besar dari 0 . Sementara jika $G$ graf reguler berderajat $k$, maka jumlah dari nilai eigen matriks Laplacian dan nilai eigen matriks ketetanggaan sama dengan $k$.

\section{DAFTAR PUSTAKA}

[1] Anton, Howard. 2000. Dasar-dasar Aljabar Linear. Edisi 7, Jilid 1. Interaksara,

[2] Biggs, Norman. 1993. Algebraic Graph Theory. Second Edition. Cambridge University Press, New York.

[3] Fiedler, Miroslav. 1973. Algebraic Connectivity of Graphs. Czechoslovak Mathematical Journal vol. 23. Praha.

[4] Jacob, Bill. 1990. Linear Algebra. W. H. Freeman and Company, New York.

[5] Juhasz, F. 1982. On The Spectrum of a Random Graph. Colloq.Math.Soc.J.Bolyai 25. North-Holland,Amsterdam.

[6] Kolman, Bernard. 2004. Elemetary Linear Algebra. $8^{\text {th }}$ Edition. Pearson Education, New Jersey.

[7] Leon, Steven. 2001. Aljabar Linier dan Aplikasinya Edisi ke-5. Erlangga, Jakarta.

[8] Wilson, Robin J., and John J. Watkins. 1990. Graph An Introductory Approach: A First Course in Discrete Mathematics. John Willey \& Sons, Inc, New York.

[9] Yacoub, Wafa.2004. A Thesis : Eigenvalues of Graphs :Algebraic Connectivity and Acyclic Matrices. The faculty of The Department of Mathematics. San Jose State University, San Jose States. 